\title{
Warwick Kerr: a Amazônia, os índios e as abelhas
}

\author{
ENTREVISTA A MARCO ANTÔNIO COELHO
}

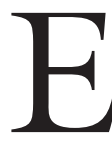

NTRE OS DECANOS das ciências naturais no Brasil, dedicado sobretudo aos desafios da Amazônia, Warwick Estevam Kerr destaca-se por cumprir seu dever como cientista e professor, trabalhando com o mesmo entusiasmo de um jovem. Assim o encontramos no campus da Universidade Federal de Uberlândia, em Minas Gerais.

Nascido em 1922, em Santana do Parnaíba, em São Paulo, Kerr formou-se engenheiro agrônomo - vencendo as etapas do doutoramento e da livre-docência na Escola Superior de Agricultura "Luiz de Queiroz", onde foi professor, e, por quatro meses, chefe do Departamento de Genética. E todos reconheciam que o laboratório de Genética, em Piracicaba, era "um dos mais bem montados da USP".

Como biólogo e geneticista, Kerr iniciou sua carreira acadêmica numa época em que houve um extraordinário desenvolvimento dessas disciplinas em São Paulo, graças à presença de eméritos cientistas, como Carlos Arnaldo Krug, Friedrich Gustav Brieger, André Dreyfus e Theodosius Dobzhansky, este considerado como um dos maiores geneticistas do século XX. Incentivado por Dobzhansky, Kerr estagiou e deu aulas em diversas universidades norte-americanas (Louisiania, Califórnia, Wisconsin e Columbia University, em Nova York.)

Em 1955, Kerr foi chefe do Departamento de Biologia em Rio Claro no início da Unesp. Em 1965, assumiu a

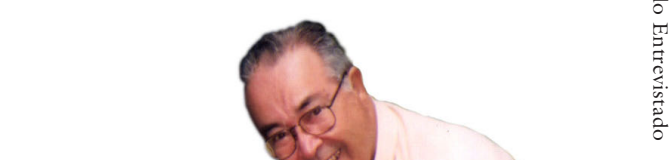
chefia do Departamento de Genética da Faculdade de Medicina da USP - Ribeirão Preto, da qual se tornou professor titular por concurso em 1971. 
Warnick Kerr foi também o primeiro diretor científico da Fapesp, no início de 1962, por sugestão de Paulo Emílio Vanzolini e Crodowaldo Pavan, tendo sido nomeado pelo governador Carvalho Pinto. Pediu demissão desse cargo em 1964, um mês antes do término de seu mandato, a fim de montar o Departamento de Genética da Faculdade de Medicina de Ribeirão Preto. Além de contribuir decisivamente na organização dessa entidade, Kerr empenhou-se na fundação de instituições com os mesmos objetivos da Fapesp em outros estados brasileiros.

Entre 1975 e 1979, transferiu-se para Manaus para reorganizar o Instituto Nacional de Pesquisas da Amazônia, o Inpa, com forte apoio do dr. José Dion de Melo Teles, presidente do CNPq. A respeito de sua participação inicial nesse instituto, Kerr relata que, quando chegou à capital do estado do Amazonas, no Inpa trabalhavam apenas um mestre e um doutor. Quando saiu do Inpa, este contava com cinqüenta mestres e sessenta doutores, quatro cursos de pós-graduação e 233 pesquisadores. "O que fizemos", diz ele, "foi mandar para o sul ou para o exterior todo o pessoal aproveitável para fazer mestrado e doutorado. Também contratamos pessoal local ou de outras regiões, e até mesmo no exterior." Depois de aposentar-se da USP em janeiro de 1981, Kerr foi para o Maranhão, onde permaneceu oito anos. Além de criar o Departamento de Biologia, foi reitor da Universidade Estadual do Maranhão. Em 1999, foi chamado de volta a Manaus para dirigir o Inpa, por mais três anos.

Presidente da Sociedade Brasileira para o Progresso da Ciência, desempenhou essa missão de 1969 até 1973, período marcado pelas inúmeras crises entre o governo militar e a comunidade científica e universitária, o que levou a SBPC, sob a liderança de Kerr, a uma clara postura de repúdio às arbitrariedades praticadas pela ditadura. Foi preso duas vezes (em 1964 e 1969).

Após terminar suas atividades no Maranhão, Kerr foi convidado a continuar suas pesquisas na Universidade Federal de Uberlândia. Embora aposentado, ao completar setenta anos, em 1992, nesta universidade orienta alunos na pósgraduação, dá aulas de Genética dos Hymenoptera e realiza suas próprias pesquisas.

Em toda sua longa, fecunda e empolgante carreira como cientista, a vida de Warwick Estevam Kerr foi assim sintetizada num depoimento registrado pela Fapesp: "no meio acadêmico, a primeira associação que se faz ao nome de Warwick Kerr é a de um formador de grupos, de um catalisador de pessoas voltadas para o desenvolvimento científico". Além de ser membro da Academia de Ciências do Brasil, em 1990, Kerr tornou-se o primeiro brasileiro a pertencer à Academia de Ciências dos Estados Unidos.

No dia 10 de janeiro do corrente ano, EsTUDOs AVANÇADOs entrevistou Kerr em Uberlândia. Segue-se aqui um resumo de suas declarações a Marco Antônio Coelho, editor-executivo da revista. 


\section{A ciência e a Amazônia}

Estudos Avançados - Como o senhor analisa as atividades cientificas e tecnológicas, realizadas no Brasil, tendo em vista os problemas da Amazônia?

Warwick Kerr - Penso que estão se desenvolvendo de maneira satisfatória. Mas se o Instituto Nacional de Pesquisas da Amazônia (Inpa), que conheço por dentro, e as universidades localizadas na Amazônia tivessem verbas dez vezes maiores, os resultados seriam vinte vezes maiores. Em resumo, seu trabalho é de ótima qualidade, mas precisa ser multiplicado por dez.

Vou citar um exemplo. Uma de minhas filhas recebeu de presente, quando eu era diretor do Inpa, uma bolsa muito bonita feita de couro de pirarucu. Usoua durante dez anos até que a bolsa foi roubada. Provavelmente a ladra que a roubou deve a estar usando até hoje, porque o couro de pirarucu é resistente. Não é vendido no mercado, mas diariamente são jogadas fora milhares dessas peles, em pesquisa relaizada pelo Inpa. Todavia, nunca apareceu uma firma que utilizasse o couro de pirarucu. Por isso afirmo que, se tivéssemos maiores recursos para pesquisa e empresários criativos, conseguiríamos atender a inúmeras outras necessidades da Amazônia.

Estudos Avançados - O senhor julga que a comunidade científica e o governo brasileiro atuam de conformidade com a magnitude dos problemas da Amazônia?

Warwick Kerr - Evidentemente não, pois o governo não está nos dando os recursos de que necessitamos. Porém, agora, estou com muita esperança no atual governador do estado do Amazonas, Eduardo Braga. Tenho confiança nele porque colocou pessoas competentes em funções de grande responsabilidade. Por exemplo, a professora Marilena Correa da Silva, secretária de Ciência e Tecnologia é de primeiríssima classe. Além disso, no Amazonas existe uma fundação de amparo à ciência nos moldes da Fapesp - a Fapeam, que auxilia pesquisas com recursos de sua receita. (Um por cento da arrecadação de impostos estaduais e $0,7 \%$ da receita de empresas da Zona Franca, que, com isso, têm impostos diminuídos).

Estudos Avançados - Como diretor por duas vezes do Inpa, como o senhor analisa a atuação das entidades de pesquisa localizadas na Amazônia, assim como o trabalho dos pesquisadores sediados em institutos no sul do país, mas que estão voltados para os desafios científicos da Amazônia? Seriam necessárias correções nos rumos dessas atividades?

Warwick Kerr - Não é necessária correção nos rumos dessas atividades. O básico é colocar um número muito maior de pessoas na pesquisa de questões que não estão sendo estudadas. E quando designarmos uma pessoa para enfrentar uma questão, não se deve colocar nele um "tapa olho". O cientista não é burro. Não tendo "tapa olho", não só realizará o que lhe pedirem, mas fará outras coisas interessantes. Sou um cristão meio esquisito, porque não acredito em diabo. Então, não sou aceito em religiões cristãs que estejam muito endiabradas para meu gosto. Mas tenho capacidade para pesquisar e, como tentei no 
Inpa, atuo seguindo aquilo que chamo de praticar o Segundo Mandamento "amarás o teu próximo como a ti mesmo". Trabalho com todo amor para o que é fundamental para o povo da Amazônia e de Uberlândia. Essa importância varia muito. Por exemplo, se eu melhorar a pesca do pirarucu isso pode ser ruim, porque descobrirei um jeito mais fácil de pegá-lo em grandes quantidades. Mas se usar essa inteligência para também criar pirarucu em grande quantidade talvez resolva o problema. O pirarucu é um peixe carnívoro, que vem à tona a cada dois ou três minutos para respirar; é impressionante como pega uma piranha. Assim, temos de estudar com maiores detalhes o pirarucu na sua reprodução. Outros peixes estão bem estudados, como o tambaqui. Lá no sul há um parente do tambaqui - o pacu. Este pode ser cruzado com o tambaqui, gerando o tambacú. Não sei se é ou não fértil. Um chinês disse-me que o tambaqui é um dos peixes mais criados na China.

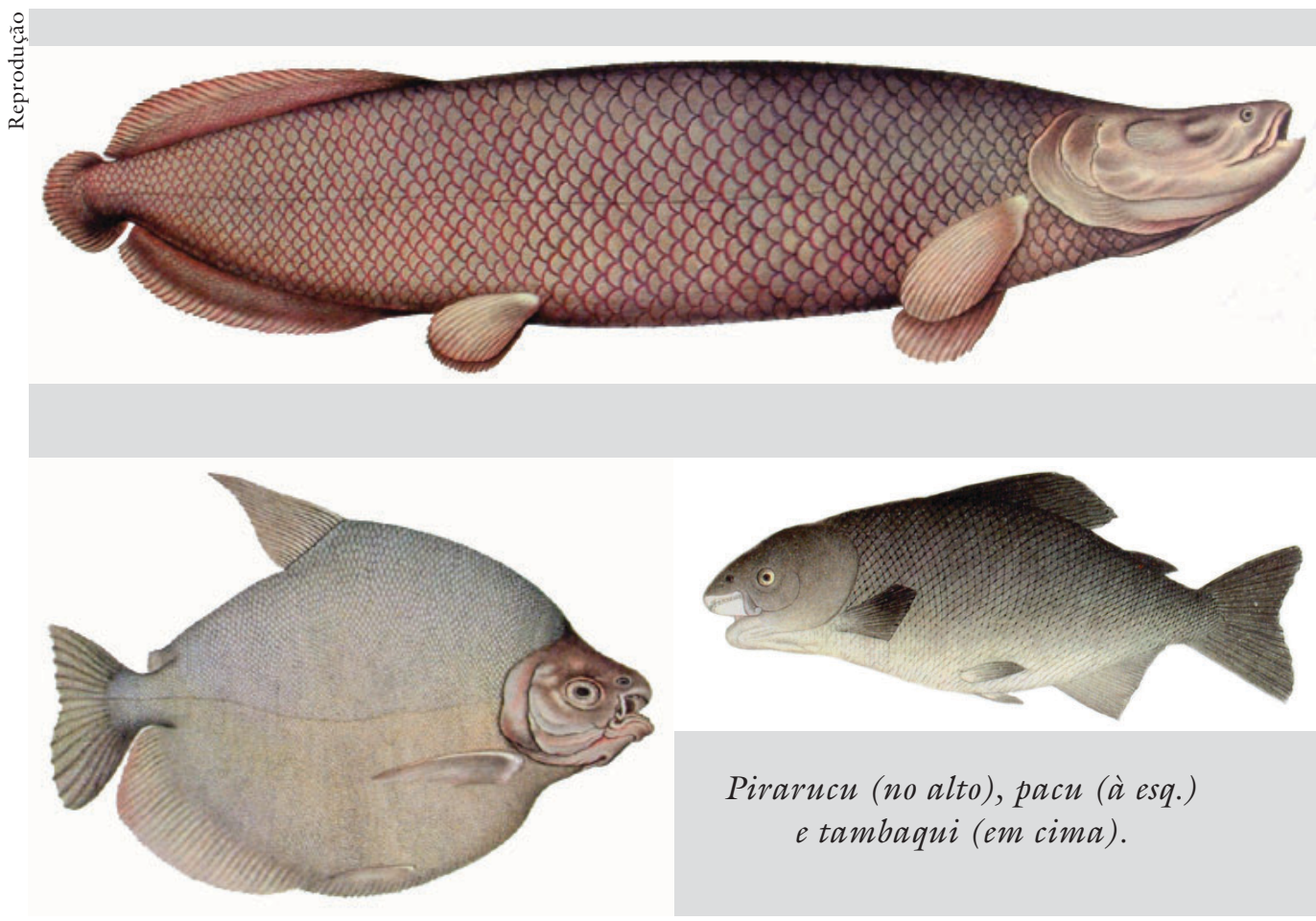

Em relação aos problemas da Amazônia que devem ser estudados por nós, reuni, em 1975, um grupo de pesquisadores das principais organizações científicas da Amazônia a fim de realizarmos o l⿳ Planejamento Estratégico do Inpa. Depois desse fizemos mais seis "Planejamentos Estratégicos" no Inpa, sempre buscando os temas prioritários que deveríamos atacar. Levantamos, por exemplo, quais as principais doenças, pois a Amazônia está cheia de doenças que não são estudadas. Há uma análise, penso que do Instituto Oswaldo Cruz, mostrando que entre Belém e Manaus existem mais arbovírus do que todos aqueles conhecidos no resto mundo Pois bem, então essa é uma grande pesquisa a ser feita. (Arbovírus são vírus transmitidos pelo ar, pelos insetos ou pelos ventos.) 
São importantes as madeiras, as abelhas, os peixes, um mamífero muito perseguido - o peixe-boi; as plantas domesticadas pelos índios etc. Deveríamos realizar um maior número de pesquisas, como, por exemplo, sobre a quantidade de fungos na Amazônia, sobre as árvores frutíferas e a composição dos seus frutos, a respeito da domesticação de animais etc. Diversos grupos de pesquisa fora do Inpa são também bons, como os da Embrapa e da UFPA. A nossa camaradagem com a Embrapa sempre foi boa. Procuramos não trabalhar no mesmo assunto. Infelizmente, a crise do petróleo afetou muito o Inpa especialmente nas nossas atividades no Acre, Rondônia, Roraima, Aripuanã e em outros estados da Amazônia (Mato Grosso, Tocantins e Maranhão).

Estudos Avançados - Como deveria ser o entrosamento de pesquisadores estrangeiros com as entidades científicas brasileiras?

Warwick Kerr - Quando fui diretor do Inpa tínhamos cinco departamentos grandes. Um deles era o de peixe e pesca. A pessoa mais especializada nessa área, na Amazônia, naquele tempo, era o prof. Wolfgang Junk, alemão, amigo do Brasil. Coloquei-o como responsável por esse grupo por três anos. Tentei algum brasileiro antes? Sim, tentei contratar bons pesquisadores que trabalhavam com o Vanzolini, mas ninguém quis ir para Manaus. Quando o dr. Junk voltou à Alemanha, felizmente consegui um cientista notável que aceitou a chefia do Departamento de Peixe e Pesca Interior, o dr. Miguel Petrere Júnior. Ele orientou o Departamento e teve uma excepcional produção de trabalhos sobre a pesca na bacia Amazônica. Não tive o mesmo êxito com colegas da Esalq. Por isso, para a direção do novo Departamento de Agronomia, convidei um argentino Dr. Alejo Van Der Pahlen. Ele dirigiu muito bem esse departamento até quando adoeceu, talvez em conseqüência do clima da Amazônia. Ele foi para a Itália, para a FAO, onde faleceu. Foi substituído pelo dr. Hiroshi Noda.

É ótimo quando temos pessoas de competência internacional e que tenham amor ao Brasil. Contudo, ocorreu um caso desagradável. Para o programa de botânica, contratei um estrangeiro que havia sido indicado por uma entidade, a fim de formar uma equipe com pesquisadores brasileiros. Mas, ele não formou equipe alguma, pois trabalhava por conta própria e nunca ficamos sabendo qual era o seu trabalho. Certo dia ele disse-me que precisava fazer coletas de material botânico na floresta que se estende de Manaus até a fronteira com a Venezuela. Ele entrava na mata e de dez em dez quilômetros tirava um tolete de terra de mais ou menos cinco quilos. Quando desembarcou com essas amostras, o pesquisador brasileiro que o acompanha informou-me. Abordei-o, perguntando por que ele estava fazendo aquilo. Respondeu-me que não tinha de prestar esclarecimentos a respeito de seu trabalho. Determinei, então, a um de meus auxiliares, que jogasse fora todas aquelas amostras.

Houve um outro caso. Esteve conosco um pesquisador da PUC, um padre. Eu gostava muito dele. Ele voava sobre a Amazônia, indo e voltando, e tinha um cintilador a bordo. Com isso ele ficava sabendo os lugares em que havia jazidas de 
urânio e rádio. Ele levou tudo isso para os Estados Unidos. Naquela época eu mesmo achei que aqueles dados teriam pouco uso para nós. Hoje, já não penso assim, porque, onde houver lugares que tenham radiação, eles deveriam ser assinalados e informados ao Inpa e à Embrapa. As castanheiras (Bertholletia excelsa), em terreno com tório, absorvem-no junto com o cálcio. Assim, tudo isso foi de graça para os Estados Unidos, quando seria importante para o Brasil pelo menos saber onde estão suas jazidas de urânio, e onde não devemos plantar castanheiras.

Estudos Avançados - O governo brasileiro nunca controlou atividades como essa? Não há um órgão oficial que fiscalize essas pesquisas?

Warwick Kerv - Legalmente há. Junto com cada cientista estrangeiro devemos colocar um cientista brasileiro, mas não há dinheiro para cumprir a lei. Enfim, o entrosamento entre pesquisadores estrangeiros e brasileiros deve ser feito na base de honestidade, e com segurança. Mas esse relacionamento depende muito das pessoas. Tive problemas com algumas e fiquei satisfeito com a maioria. Quando o pesquisador vem com o pensamento de trabalhar e servir à nação que o hospeda é uma coisa. Porém, quando vem com o espírito de espionar ou roubar é outra. Não podemos tomar medidas padronizadas face ao comportamento dos pesquisadores estrangeiros que atuam no Brasil. Cada caso é um caso. Uma das medidas que ultimamente tem prejudicado nossos cientistas é a proibição de mandar insetos secos para um especialista no exterior, a fim de que o estude e o determine. Essa proibição tem acarretado problemas para nossa taxonomia.

\section{A lição de um agrônomo}

Tenho um amigo, pesquisador do Inpa, o dr. Hiroshi Noda, agrônomo santista que deu sua vida para a Amazônia. A mulher dele é a dra. Sandra Noda, socióloga. Ele trabalha pesquisando as plantas que os Ticuna comem ou usam e acompanha a vida agronômica deles. Pois bem, todas as vezes que ele ia visitar um desses Ticuna, verificava que a maioria das crianças estava com diarréia. Levou um médico e este constatou que elas bebiam água contaminada. $\mathrm{O} d r$. Hiroshi teve então a idéia de arranjar dinheiro para furar um poço de vinte a quarenta metros, comprar uma bomba para tirar água do poço, montar uma caixa d'água a quatro metros de altura, e um motor movido a energia de luz solar. Trouxe engenheiros para montar tudo, sempre trabalhando com índios. Sucesso! Por isso arranjou dinheiro para furar mais seis poços. Formou um conjunto desses em sete comunidades. A taxa de disenteria caiu de $80 \%$ para 15\%. A Igreja Católica, num outro lugar, está fazendo a mesma coisa, e a lição foi seguida por uma igreja protestante. Assim, por causa do bom exemplo de um agrônomo idealista a população está aumentando, porque não morrem mais tantas crianças como antigamente sucedia. A população que mora nesse lugar tem mais saúde. Agora falta educação sexual adequada para não haver ali uma explosão populacional.

Isso acontece sempre com nossos cientistas inteligentes e humanistas. $\mathrm{O}$ dr. Noda foi estudar alimentos indígenas e acertou a mão em outra coisa completamente diferente. Ele e a esposa conseguiram que todas as montagens e des- 
montagens desse equipamento sejam feitas somente pelos índios. Por isso os índios as controlam direitinho e estão funcionando maravilhosamente bem, aprendendo a lidar com máquinas.

O dr. Hiroshi Noda descobriu também que nas aldeias o pessoal estava sendo explorado por comerciantes que fazem comércio com seus "regatões". Compravam por uma ninharia os produtos ali produzidos e vendiam por preços absurdos as mercadorias que traziam nos seus barcos. Por isso, o dr. Noda e a dra. Sandra colocaram um aparelho de rádio no povoado e outro no campus da UFA em Benjamin Constant. Pelo rádio, a universidade informa quais são os preços das mercadorias na cidade. Assim, Hiroshi aconselhou à população a vender com pequena porcentagem de lucro para o dono do "regatão", mas não mais com aquele enorme lucro. Se eu fosse índio não iria querer um ídolo maior do que o Hiroshi Noda. É um exemplo para mim e para o pessoal que vive naquela distante região da Amazônia.

\section{O Instituto da Hiléia Amazônica}

Estudos Avançados - Depois da Segunda Guerra Mundial houve grande celeuma, na Unesco e aqui no Brasil, a respeito da criação do Instituto da Hiléia Amazônica. Como o senhor analisa hoje aquela polêmica?

Warwick Kerv - Fui contra o projeto do Instituto da Hiléia Amazônica e participei da luta pela criação do Inpa. Tivemos êxito em conseqüência da pressão militar. Na primeira vez que dirigi o Inpa (quatro anos e meio), uma visita que recebíamos todos os anos era a de grupos de generais e coronéis, que nos perguntavam sobre o que estávamos fazendo. Eu achava excelente aquelas trocas de informações porque a pior coisa é a ignorância a respeito da Amazônia.

Gostei muito de uma resposta do senador Cristóvão Buarque quando lhe fizeram a seguinte pergunta: "como humanista, o senhor não acha que a Amazônia deveria ser de todas as pessoas do mundo?". Ele respondeu mais ou menos assim: “como cientista e humanista, penso que o Louvre e os museus do mundo deveriam ser de todos, inclusive os de Nova York, Hamburgo, Roma, mas enquanto isso não acontecer quero que a Amazônia seja nossa, e só nossa”. Esse é também o meu pensamento. No entanto, temos de nos preparar desde já para que a Amazônia seja somente nossa. Não é difícil, mas muito dinheiro tem que ser gasto para montar em cada vila amazônica uma boa escola, e em cada município um ramo ou um mini-campus das universidades federais para que, em cada lugar exista boas oportunidades de estudo, de criatividade, de defesa e de trabalho. Isso é absolutamente necessário para salvarmos a Amazônia.

Naquela polêmica, depois da guerra, venceu o lado brasileiro mais nacionalista e na Amazônia fizemos o Inpa. É muito importante sermos nacionalistas. Senão, vamos perdê-la. Há tribos de índios para as quais a segunda língua é o inglês. Perto da Colômbia, a segunda língua é o espanhol, mas isso não é importante. Porque eles são Ticuna, que é uma etnia que vive nos três países - Peru, Colômbia e Brasil. 
Agora está sucedendo um fato muito interessante: com a guerra na Colômbia aumentou o número de Ticuna no lado brasileiro, mas não no lado peruano, porque o Peru está em crise e estamos economicamente melhor e, ainda, porque entre nós há muitas pessoas interessadas em salvar o índio.

Estudos Avançados - Prof. Warwick, o que o senhor está pesquisando agora?

Warwick Kerr-Continuo pesquisando as frutas amazônicas, melhorando hortaliças e dando aulas sobre abelhas, inclusive para os apicultores. A apicultura brasileira está sendo feita com a abelha africanizada. Por que africanizada? Em 1957, quando 26 rainhas fugiram por erros de manejo, passamos a ter uma abelha nova: a africanizada, híbrida de Apis mellifera iberica, Apis mellifera ligustica, Apis mellifera mellifera e selecionada pelo nosso meio ambiente, pelos nossos apicultores e pelos nossos cientistas.

\section{A rumorosa questão das abelhas}

Estudos Avançados - Esse fato foi muito comentado e criou um grande problema, não foi assim, professor?

Warwick Kerr - Sim. De 1957 até 1964 essas abelhas cruzaram-se com as alemãs, italianas e portuguesas. Porém, houve um grande problema: os apicultores colocavam seus apiários próximos aos galinheiros, pocilgas, cocheiras. Houve mortes de galinhas, porcos, cavalos, e a mortalidade de gente que era 120 por ano passou para 180. O grupo de Ribeirão Preto (Kerr, Lionel, Stort, vários alunos, três técnicos e mais tarde David De Jong e Ademilson Espencer Soares) conseguiu desenvolver várias técnicas, algumas muito simples, para controlar a exploração econômica dessas abelhas, como colocar os apiários longe das casas de moradia, dos galinheiros e cocheiras etc.; depositar as colméias em banquetas isoladas (ou em canos grossos de esgoto), usar fumigadores maiores, macacões, botas, por máscaras e luvas, sempre; fazer rainhas, escolher as colméias mais produtivas, mais mansas, mais resistentes a ácaros e enfermidades. Porém, um avanço fundamental foi dado em 1965 e 1966 com a diminuição da agressividade das abelhas, o que era um grande problema.

Cinco anos depois, a questão estava praticamente resolvida. O que fizemos? Compramos vinte rainhas ótimas, italianas dos Dadant (de Ohio) mansas e de alta produtividade; fizemos enxertia obtendo 25 mil rainhas virgens; introduzimos em vinte e cinco mil núcleos fortes e, creio, dezoito mil foram aceitas e produziram milhares de zangões italianos. Logo os apicultores viram que não adiantava ter uma população mansa, como se tinha com as abelhas italianas, mas que se fornecia uma reduzida produção de mel, duas a três vezes menos produtiva do que a africanizada. A baixa produção das italianas era causada por vários fatores, inclusive porque não resistiam a um ácaro muito grande, Varroa destructor, que provocava enorme estrago nas colméias, ao ponto de baixar a produtividade da apicultura em dezenas de países. Também, as africanizadas jogam fora as larvas doentes e mortas. 
A nossa produção normalizou-se porque os apicultores aprenderam a lidar com a abelha africanizada. Esta tem pequenos detalhes, citados acima, mas que são muito importantes. É mais limpa do que as outras. Onde existe vassourinha (em Minas chama-se alecrim) há produção de própolis verde, que é dez a quinze vezes mais caro do que o marrom. Para se produzir própolis verde, a abelha corta atrás das folhas da vassourinha, (Baccharis dracunculifolia) e suga (o verde é a clorofila). Com essas vantagens, a nossa apicultura foi para frente em alto grau. Esse fato se deve exatamente à abelha africanizada que tem essas vantagens, o que não acontece com as abelhas de outras procedências.

Diante do erro cometido com as abelhas africanas, em 1957, eu não esperava que iria dar a volta por cima. Pensava que teria uma vida desgraçada para o resto dos meus dias. Até 1978, as mulheres franziam a testa mostravam-me para os filhos e diziam: "aquele é o homem que introduziu a abelha brava no Brasil". De 1979 em diante, porém, tudo mudou. Passaram a tirar fotografias minhas e falavam: "esse é o homem que salvou nossa apicultura. Por causa dele o papai comprou caminhão novo". Enfim, durante catorze anos vivi uma tragédia com a introdução no Brasil das cinqüenta rainhas da África do Sul e de uma da Tanzânia. Agora, minha mulher acha a história até engraçada e eu, como bom caipira de Santana de Parnaíba, digo "louvado seja Nosso Senhor Jesus Cristo". E sempre fico frustado por não ter por perto meus caipiras amigos para tirarem o chapéu e dizerem: "E para sempre seja louvado, amém".

Ensinei aos índios de cinco etnias da Amazônia a lidar com abelhas sem ferrão, o que é a minha especialidade. O Fernando Oliveira inventou em Manaus uma colméia muito útil e prática, baseada no método do dr. Paulo Nogueira Neto para a criação de colônias das abelhas jupará, jandaira, uruçu-boca-de-renda. Esta última é provavelmente a abelha mais inteligente que existe. Junto com o Fernando, preparamos um folheto com as instruções para a utilização dessa caixa, com o título "Divisão de uma colônia de jupará (Melipona compressipres manaosensis) usando-se uma colméia e o método de Fernando Oliveira".

O que descobrimos? Que se os índios e os ribeirinhos montarem colméias com essas caixas, conseguirão aumentar sua rendas e deixei com eles cerca de trezentas colônias. Ao voltar para Uberlândia, entreguei as colônias e o problema nas mãos da dra. Gislene. Hoje, ela, com seis alunos e técnicos, conseguiu que índios, ribeirinhos e sitiantes tenham um total de oito mil colméias de Santarém a Tabatinga. Esse trabalho tem imensa repercussão ecológica, pois se as abelhas de cada colméia fazem diariamente 1.400 viagens, supondo que cada abelha visite apenas quatro flores por viagem, com as oito mil colméias serão 16,8 trilhões de flores visitadas durante um ano (trezentos dias), fecundando as flores. Isto resultará em frutos, sementes, plantas e fornecerá alimento para aves, mamíferos, répteis, peixes, artrópodos, na Amazônia. Então, um dos melhores movimentos para a conservação do meio ambiente reside no aumento do número de colméias de abelhas sem ferrão. É um argumento ecológico, mas há também o econômico, 
porque os índios podem ganhar um bom dinheiro com as abelhas. É também um argumento social, pois essas abelhas passarão a ser cuidadas pelas mulheres e até pelas crianças. Essa é uma das atividades que deveria ser espalhada pelo Brasil inteiro.

\section{Frutas e hortaliças}

\section{Estudos Avançados - O senhor está empenhado em outras pesquisas?}

Warwick Kerr - Além das abelhas, tenho me dedicado a fruteiras e hortaliças. Ultimamente estudo especialmente o camu-camu (Myrciaria dubia), que é da mesma família da jabuticaba. Mas é tão ácido que só ao falar nela começa a me doer a garganta, como acontece quando se chupa limão. A história do camucamu lembra a descoberta da vitamina $\mathrm{C}$ do limão. Outras frutas também possuem vitamina C - goiaba (140 mg), laranja (32 mg), caju (400 mg), acerola ( $1200 \mathrm{mg}$ ) etc. Agora o dr. Kaoro Yuyama descobriu que o camu-camu é a fruta que mais contém vitamina C $(2200 \mathrm{mg}$ ) (em alguns lugares da Amazônia chamam o camu-camu de "fruta-de-tambaqui"). A planta do camu-camu dá na beirada dos rios e riachos. Resolvemos plantá-la nas margens dos córregos porque quando chega a época de dar flor e fruto a água abaixa um pouco. Com isso, a planta toda florida enche-se de abelhas, atraídas pelo cheiro maravilhoso das flores do camu-camu. Testamos seiscentas sementes em Uberlândia e estamos com umas dez plantas que agüentaram o cerrado pobre daqui do Triângulo Mineiro. Dessas plantas, cinco produzem uma grande quantidade de frutas. Mas não sabemos ainda porque num ano elas produzem bastante, mas no ano seguinte, ou nos dois anos seguintes, não sucede a mesma coisa.

O mineiro e o goiano adoram o pequi. Para eles tenho uma notícia interessante: descobrimos uma planta de pequi sem espinho e que é mais doce que o pequi que tem espinhos no caroço. Agora vamos fazer uma coleção de pequizeiros de três espécies. Para isso, vamos trazer pequizeiro do Maranhão e do Amazonas que são espécies diferentes. Vamos cruzar tudo isso para tentar obter pequis mais doces e sem espinhos. Viva a esperança!

Igualmente conseguimos obter uma alface que contém dez mil unidades de vitamina A, o que é muita coisa, porque normalmente a alface apresenta apenas quatrocentas a oitocentas unidades dessa vitamina. Sua origem foi lá no Maranhão: um hortigranjeiro telefonou-me para informar que na plantação dele (da alface Maioba), uma dentre quinhentas plantas tinha cor verde escuro. Ensinei-o a fazer sementes e, a partir disso, depois de sete anos de seleção, chegamos a uma alface - a Uberlândia 10.000 - que tem dez mil unidades de vitamina A. Enfim, para ser bom "melhorista" tem de ter grandes números, olho vivo e... sorte.

\section{O problema das patentes}

Estudos Avançados - O Brasil teria algum rendimento econômico se os cientistas registrassem patentes de suas descobertas na Amazônia?

Warwick Kerr - Não concordo com o sistema de patentes porque reduz a 
produção e o desenvolvimento científico e tecnológico. Não entendo porque devo guardar só para mim aquilo que descobri, porque fui pago exatamente para fazer esse trabalho. Na verdade, os cientistas têm as qualidades e os defeitos das demais pessoas. Um desses defeitos é a desonestidade e, lamentavelmente, tem ocorrido que alguns pesquisadores roubam descobertas e trabalhos de outros cientistas. Tenho um colega aqui que, quando faz uma descoberta, imediatamente solicita a patente, porque atua num meio muito competitivo. É um bom cientista, excelente mesmo. Em sendo assim, esse colega requer patente para não ser roubado, inclusive porque já houve um antecedente curioso. Ele enviou um artigo para uma revista e o texto foi recusado. Passado algum tempo o texto foi publicado em outra revista, mas apresentado como da autoria daquela pessoa que anteriormente examinara o artigo.

Não solicito patentes e entrego a qualquer pessoa as sementes dos vegetais que estou pesquisando, junto com o meu pedido de que façam suas próprias sementes a partir das minhas. Essa é a minha opinião. Se quisesse ganhar dinheiro, minhas sementes me deixariam muito rico, como seria o caso daquelas sementes de alface, sobre a qual lhe relatei e recebi propostas de compra.

Estudos Avançados - Mas bancando o advogado do diabo, é conbecido e sempre citado o caso daquela pesquisa do prof. Sérgio Ferreira, de Ribeirão Preto, que descobriu uma substância proveniente do veneno da jararaca, cujo principio ativo é utilizado na fabricação de um remédio para hipertensão. No entanto, essa substância foi patenteada por um poderoso laboratório.

Warwick Kerr - Esse é o único caso que é muito falado mas... falado errado! Mas se o Brasil se empenhasse em realmente defender seus interesses, o que deveríamos fazer? A empresa estrangeira que patenteasse algum remédio de planta brasileira deveria ser proibida de atuar no Brasil, e pronto. A propósito, é bom citar um caso acontecido na Índia. Lá existe uma planta cujo nome vulgar é nim (neem=Azadirachta indica), que é boa para o tratamento da cárie de dentes e ótimo inseticida natural. Uma firma norte-americana fabricou um remédio e um inseticida utilizando nim. Esses produtos foram vendidos na Índia, sendo que estava embutido no seu preço uma remuneração de oito a dez por cento pelo uso da patente. Em razão disso, a Índia proibiu a entrada desses produtos e não permitiu que se tirasse mais nim de seu país. Ademais, tomou outras medidas contra a empresa. Esta, porém, logo anunciou que na Índia não se acrescentaria ao preço dos produtos do nim o da patente. Então, é isso que devemos fazer.

Por causa da sua pergunta telefonei ao dr. Sérgio Ferreira. Ele disse-me que há trinta anos atrás não havia patenteamento de produtos naturais. Hoje tem patente até de gene, o que não é aceito por vários países, inclusive pelo Brasil. Nossa lei diz que uma instituição pública ou privada tem o direito de explorar uma cultivar por quinze anos, ou seja, equivale a patentear por quinze anos. $\mathrm{O}$ agricultor pode usar a semente da cultivar mas não pode vender. Nos EUA o agricultor assina uma espécie de contrato no qual se compromete a não vender a 
semente patenteada. Lá ao pesquisador é permitido usar a cultivar para fazer cruzamento. No caso do dr. Ferreira não houve roubo nem patente envolvida diretamente. Ele constatou que o efeito da bradimicina era muito ampliado se misturado ao sangue que tivesse veneno da jararaca. Esse material serviu para uma firma americana sintetizar o capoten, hoje usado para controlar pressão.

Estudos Avançados - Bancando novamente o advogado do diabo, do ponto de vista do aproveitamento da biodiversidade, na fabricação de cosméticos não seria correto obtermos algum resultado financeiro com a exploração dessa riqueza da Amazônia?

Warwick Kerr - Citei-lhe o caso do cheiro maravilhoso da flor do camucamu. Num negócio desse tipo, que não tem importância para a saúde, fico pensando que talvez valesse a pena solicitar a patente e ganhar dinheiro com ela... Todavia, naquilo que interessa à saúde não concordo. Não sei como é agora, mas no passado recente a França não permitia nenhuma patente relacionada com a fabricação de remédios.

\section{A política de Lula}

Estudos Avançados - Professor Kerr, qual sua opinião a respeito da política governamental em relação aos problemas educacionais e às atividades científicas e tecnológicas?

Warwick Kerr - Do ponto de vista da economia, o regime nunca esteve tão bem como está agora, desde que nasci. O real frente ao dólar melhorou nesses dois anos e meio. O dólar baixou de preço. Todavia, para os pobres a situação não está tão boa assim. O Lula se distanciou de professores como eu. Desejei conversar com ele e dar-lhe algumas sugestões, inclusive sobre como criar empregos, porque ele me conhece e já foi meu hóspede quando eu era o reitor da Universidade Estadual do Maranhão. Mas o presidente Lula está fechado numa torre e cercado por meia dúzia de pessoas. Recebe os milionários mas não procura os professores. Essa reforma universitária que está sendo proposta, na verdade, é uma contra-reforma, porque é um absurdo entregar recursos públicos às universidades particulares, cujo ensino é comprovadamente de má qualidade, além de não fazerem pesquisa, nem extensão. Logo, não tem as características de universidade e a mim parecem ser um negócio rendoso que vai ficar ainda mais rendoso com as bolsas.

Recebo do CNPq apenas um pequeno auxílio para minhas pesquisas. O senhor mesmo testemunhou como vou pagando os empregados que me auxiliam plantando centenas de mudas de pequi. Sei que o CNPq está com pouco dinheiro, mas não estou satisfeito com a situação atual. Outro dia, desesperado, telefonei para um de seus diretores solicitando um auxílio de oito mil reais para pagar algumas despesas, pois minhas pesquisas foram paralisadas devido a um roubo de nossas colméias. Ele consultou o prof. Erney Camargo (presidente do CNPq) e este liberou cinco mil reais, por ser esse o limite de uma despesa emergencial. Resolvi, então, assumir a responsabilidade pelo restante e, assim, 
trouxemos 48 colméias de abelhas de Venda Nova do Emigrante para Uberlândia e já estão sendo pesquisadas por meus alunos. Isso para demonstrar que as universidade federais estão pobres e o MCT deveria prestigiar mais o CNPq, quando este, agora, tem um presidente competente.

Também acho que as verbas para a educação, nos três níveis, teriam de ser duplicadas, e na Amazônia, se quisermos salvá-la, quadruplicadas.

Estudos Avançados - Professor Kerr, qual sua opinião a propósito do asfaltamento da rodovia Cuiabá-Santarém?

Warwick Kerv - Conheci a rodovia Brasília-Belém quando estava sendo construída. Era mata fechada dos dois lados da estrada. Agora, o que vemos nela é o desmatamento de vinte a cinqüenta quilômetros de cada lado. Como não há fiscalização do governo, o quadro é dramático. E não tenho notícia de que pelo menos um fazendeiro ou madeireiro esteja preso por dez anos por desmatar uma floresta, e por quinze anos se for um Parque Nacional. O mesmo vai acontecer com a Cuiabá-Santarém.

O caso do Pontal do Paranapanema, em São Paulo, é uma vergonha. O Ademar de Barros deixou que seus amigos invadissem as terras do Parque como se fossem áreas devolutas e agora os sem-terra querem invadir aquelas áreas. Ótimo invasão em cima de invasão; poderiam pelo menos dividir em partes iguais...

Na verdade, não temos uma política para salvar as florestas. Na Alemanha, quando é construída uma rodovia numa floresta, se alguém atropela um animal silvestre, recebe uma penalidade elevada. Aqui, nada acontece quando um motorista pratica um desses crimes, liquidando veados, tamanduás e emas. Sei de casos de pessoas que, ao vislumbrarem um animal silvestre, sacam o revólver e atiram por mero prazer. Por isso sou contra o asfaltamento dessa rodovia até que a sociedade aprenda a cuidar das reservas florestais e haja leis mais fortes contra os invasores. Conservação da natureza é uma questão de educação, das escolas primárias até as universidades.

\section{A questão dos transgênicos}

Estudos Avançados - Como devemos agir para impedir o prosseguimento da devastação florestal na Amazônia? O ecoturismo poderia auxiliar a defesa do meio ambiente?

Warwick Kerv - O ecoturismo, se não for bem feito, acarreta sérios problemas. Na Suíça, que realiza um excelente ecoturismo, não permitem que os suíços se misturem com os turistas. Somos uma vergonha internacional por não prendermos os organizadores do turismo sexual. O manejo controlado do corte de madeiras (madeiras certificadas) tem um defeito gravíssimo e por isso considero estranho o fato de uma organização que admiro como a WWF aceitar esse plano, porque afeta a biodiversidade. Pois bem, então, em vez de pegar uma coisa séria como a descaracterização e o empobrecimento de nossas florestas, a ministra Marina Silva engajou-se de forma equivocada na questão dos transgênicos. Eu admirava e admiro essa ministra, mas ela vem se opondo erradamente aos 
transgênicos, pois essas pesquisas são indispensáveis, pois nada mais são que um método de melhoramento. Mas será que vamos ter algum transgênico ruim? Claro que vamos! Já houve o caso de uma cultivar de milho em que só nela aconteceu um problema na produção de linhagens masculinas estéreis. Tivemos também outras coisas terríveis com seleção de mandioca (macaxeira). O pesquisador quis fazer uma mandioca rica em proteína e em quatro anos fez a mandioca mais venenosa, rica em HC rica em ácido cianídrico (HCN). Como bom pesquisador, jogou tudo fora. E outras ainda vão acontecer. No entanto, o método de melhoramento dos vegetais e animais não deve ser impedido e sim bem controlado. Não podemos deixar que firmas estrangeiras controlem nossa produção de sementes para não haver a falta de sementes de hortaliças como sucedeu em 1940, poucos meses depois do início da Segunda Grande Guerra.

Estudos Avançados - O que deve ser feito para preservarmos a biodiversidade em nossas florestas?

Warwick Kerr - A primeira coisa fundamental é não deixar cortar. Agora estão querendo tirar madeira até mesmo em florestas do governo, o que é uma loucura, como o que pretendem fazer no Mamirauá, no rio Juruá. Tem gente até afirmando que o efeito das caçadas nessas reservas não é pernicioso. E os destruidores estão começando uma campanha de difamação dos conservacionistas.

O índio caça de qualquer maneira, assim como o pobre. O importante é que eles respeitem o limite de 3\% que os especialistas dizem que é o suportável. Caso contrário acontecerá o que sucede na África. Estão acabando com a fauna da África (inclusive de gorilas e elefantes), porque em muitos países daquele continente não são fixados limites para caçadas.

\section{Relacionamento com os índios}

\section{Estudos Avançados - Qual é a vivência do senhor em relação às etnias?}

Warwick Kerr - Os índios são muito maltratados. Sempre que trabalhei com eles só fiz amizades. Nunca passei fome numa aldeia indígena. Em qualquer uma delas eles compartilharam sua comida comigo. Há três anos (2002), numa reunião de chefes e representantes de mais de cinqüenta etnias, em Manaus, eles elegeram David Yanomame e eu como o índio e o branco que mais trabalharam pelos índios e que mais os defenderam. Penso que no meu caso tal opinião decorreu de uma série de denúncias feitas por mim contra um massacre de Ticuna, há cinco anos. Esse fato ocorreu num lugar chamado Capacete, perto de Benjamim Constant e de São Paulo da Olivença. Foi quando houve um ataque, liderado por um fazendeiro contra um grupo pacífico de Ticuna, quando mataram catorze índios. Cheguei a viajar até Benjamin Constant para pressionar a Justiça, pois até então não se conseguia marcar o julgamento, porque todas as pessoas naquela região tinham receio de contribuir para que os criminosos fossem punidos. Escrevi mais de uma vez sobre esses fatos e dei os nomes dos mortos, dos assassinos e do mandante. 
Cada etnia é diferente das outras - costumes, adereços, alimentos. Dou um exemplo. Entre os povos do Amazonas, de Santarém até Tabatinga, todos comem ariá assada ou cozida. Já entre os Palikura (no norte do Amapá), ariá é somente consumida por mulher que deseja engravidar. Quando fui tocar na planta, três índios impediram-me e o tradutor disse-me: "doutor, se o senhor tocar nisso vai ficar grávido e os soldados do Pará virão nos matar”. Não toquei...

Estudos Avançados - Em que medida os ensinamentos dos povos da selva são utteis e devem ser aproveitados?

Warwick Kerr- Nestes últimos dez a doze mil anos os índios acumularam um conhecimento fabuloso sobre a floresta amazônica. Um dos chefes Ticuna, Adir Aldemicio Bastos, com quem sempre mantive e mantenho um bom relacionamento, ensinou-me uma coisa que nunca esqueci. "Veja - foi dizendo - um menino Ticuna de uns cinco a seis anos, se for perdido do grupo a uma longa distância da aldeia, acaba achando o caminho de volta; isto porque ele sabe que as águas de um rio só vão para um lado; então, ele desce, vai até um igarapé (riozinho) para encontrar um rio maior e chegar à aldeia. Quando tem fome, sabe que frutas pode comer e que o palmito de açaí é fácil de tirar; conhece plantas tóxicas que não pode pôr na boca. Então, um indiozinho perdido na mata sempre acha sua aldeia e não passa fome".

Os conhecimentos dos índios são notáveis, pois acumularam experiências de vários séculos, como é o caso de terríveis venenos: capahaça, mata-calado (Ryania speciosa) Mas esse conhecimento está sendo passado para livros, que nada informam sobre quais pessoas transmitiram as informações. Para mim, isso é uma informação incompleta. Por isso, publiquei dois artigos, mas os índios que colaboraram no trabalho apareceram como co-autores. Farei o mesmo quando escrever o artigo sobre o pequi sem espinho.

Os índios entendem rapidamente aquilo que ensinamos. Mas é impressionante o que eles sabem a respeito das frutas. Por exemplo, eles é que nos transmitiram o uso do abiu, da sapota, do araçá-boi, e de centenas de fruteiras. Observo, porém, que normalmente o branco se apodera dessas lições dos índios mas nada lhes dá em troca. Quando visito uma aldeia sempre levo um saco com sementes. No entanto, precisamos avaliar bem o que devemos entregar a eles, porque equívocos podem ser cometidos. Por exemplo, uma vez quando eu estava em Aripuanã, perguntei aos Cinta-larga o que desejavam. "Querem sementes? Eles responderam: "Não. Queremos calças compridas para homens e mulheres". "Por quê?" Perguntei. "Porque nas nossas andanças arranhamos muito as pernas e os pés em espinheiros e em capim navalha". Era um grupo de 22, então, deilhes vinte e duas calças e malhas.

Estudos Avançados - Recordo que, no passado, os salesianos que vieram para esta região desejaram catequizar os indios. Com os protestantes era a mesma coisa. Além disso, há esse problema em Roraima com as etnias que vivem na região da Raposa do Sol. Qual deve ser nossa postura em relação a tudo isso? 
Warwick Kerr - Respeitar o índio na sua inteireza, considerando que ele não tem mentalidade capitalista. Tem espírito de compartilhamento das coisas, o que é emocionante. Sei do caso daquele Kaiapó que deflorou uma professora. Esse índio devia estar é na cadeia, porque os Kaiapó não fazem essa besteira. Os Kaiapó eram índios guerreiros mas, agora guerreiros não têm mais lugar em parte alguma. Para fazer sua própria comida, cabe às índias o plantar e semear. Como fazem? Os homens derrubam a floresta e fazem a coivara (queimada) e esse lugar é utilizado durante três ou quatro anos. Mas as plantações são feitas pelas mulheres, pois são elas que são paridoras, sabem parir e cuidar das crianças, sabem plantar milho, mandioca, batata doce etc. Dona Teroko foi minha maior informante sobre a metodologia agronômica dos Kaiapó.

As áreas na Raposo do Sol devem ser demarcadas a favor dos índios, mas é indispensável levar em conta a segurança nacional. O Exército tem razão em defender a margem da fronteira. Por exemplo, não devemos aceitar que os guerrilheiros das Forças Armadas Revolucionárias da Colômbia, nem os fazendeiros colombianos ou qualquer outro grupo estrangeiro controlem aquela parcela de nosso país, assim como também não podemos concordar que seus inimigos entrem em nosso território. Os antiguerrilheiros são latifundiários tão ruins ou piores que os guerrilheiros. Aqueles que se dizem de esquerda têm pouca coisa de esquerda e muito de cocaína; os que são da direita apenas têm vontade de matar para ficar com as terras. Naquela disputa nenhum dos lados merece nosso apoio. Os índios sabem disso e têm receio de que os seus rapazes sejam seqüestrados para serem utilizados como soldados, apesar de sua baixa idade (doze a dezessete anos). Em resumo, o Exército brasileiro deve controlar uma faixa de nossa fronteira.

\section{As violências da ditadura}

Estudos Avançados - Durante a ditadura, a SBPC foi muito pressionada pelas autoridades militares. O que suceden com o senhor?

Warwick Kerr - Tanto eu como o Simão Matias fomos ameaçados muitas vezes, ameaças extensivas às nossas famílias. Fui preso duas vezes. Na segunda, isso aconteceu no dia da apuração de votos na eleição em que fui reeleito presidente da SBPC. O que motivou essa prisão foi meu protesto contra a tortura de uma freira católica, a madre Maurina Borges, uma pessoa muito querida que dirigia o melhor orfanato de Ribeirão Preto. É bom recordarmos aquele acontecimento. Estava eu na Faculdade de Medicina daquela cidade quando fui procurado pelo monsenhor Angélico Sândalo (hoje bispo auxiliar de São Paulo). Esse prelado solicitou-me que fizesse um exame de corpo-delito na madre Maurina, porque ela estava muito machucada em conseqüência das torturas. Respondi-lhe que não poderia atendê-lo porque esse exame só pode ser feito por um médico legista e que eu era um engenheiro agrônomo. Contudo, prometi ao monsenhor Angélico que, no dia seguinte, em minha aula de Genética na Faculdade, eu iria fazer um relato minucioso a respeito das violências sofridas por madre Maurina. 
Pois bem, no dia seguinte, quando normalmente apenas 108 alunos assistiam às minhas aulas de Genética, apareceram cerca de duzentas pessoas no salão da Faculdade. Após dar uma hora de Genética, afirmei que iria tratar também de um assunto tão importante para eles quanto a Genética. Transmiti, então, as informações que me foram dadas por dom Angélico, relatando os sofrimentos daquela freira, sobre a covardia da tortura, e dei-lhes endereços onde essa notícia poderia ser enviada. Solicitei aos ouvintes que divulgassem ao máximo a ocorrência daqueles fatos. Ao sair da aula já havia um carro da polícia aguardando-me. Levaram-me ao delegado Lamano para um longo interrogatório e me soltaram por ordem do Comando do II Exército, porque exatamente naquele dia eu havia sido reeleito presidente da SBPC, com 97\% dos votos, e minha prisão poderia repercutir mal para o governo. Entretanto, o delegado que me liberou fez questão de advertir que se eu continuasse a criticar o governo meus filhos sofreriam as conseqüências.

Estudos Avançados - Professor Kerr, como o senhor vê a atuação da Funai e do Conselho Indigenista Missionário, o Cimi?

Warwick Kerr - Meu avô Quirino sempre me dizia que aquilo que beneficia uma pessoa para o resto da vida é a cultura e a educação, afirmando que "o conhecimento não ocupa lugar". Em Manaus, perguntei a alguns Ticuna se eles estavam satisfeitos com um curso de Liderança Indígena que freqüentavam na universidade. Eles responderam: "Não, não estamos contentes. Queremos cursos de engenharia, medicina, agronomia e veterinária!"

Eu criticava muito as atividades do Cimi (católico) e do New Tribe (protestante). No entanto, quando os índios começaram a ser atacados, porque algumas pessoas desejavam ocupar suas terras, somente o Cimi e o New Tribe defenderam os índios. Se não fosse esse apoio, maus fazendeiros já teriam ocupado algumas dezenas dessas terras.

Estudos Avançados - O Inpa colaborou também para o trabalho de alfabetização na Amazônia?

Warwick Kerr - No primeiro Planejamento Estratégico do Inpa, em fevereiro de 1975, decidimos que este instituto deveria trabalhar em agricultura para o povo, nas doenças mais freqüentes, e em qualquer problema que agredisse a natureza e o povo do Amazonas. Uma professora, chamada Amélia Ramos, informou-se que os alunos do primário tinham alta taxa de reprovação e de abandono da escola. Ela achava que nenhuma cartilha era adequada. Resolvemos, então, ajudá-la nessa atividade, uma vez que as cartilhas utilizadas em Manaus eram feitas em São Paulo ou no Rio de Janeiro.

A cartilha que elaboramos resultou de um trabalho em equipe sob a liderança da professora Geraldina Porto Witter, do Instituto de Psicologia da USP. Ela contou com a minha colaboração assim como também com a do dr. Ozório Menezes Fonseca (biólogo e ótimo desenhista, pesquisador do Inpa), além da professora Maria Amélia Antunes Ramos, técnica da Secretaria de Educação do 
Amazonas. Os meninos adoraram a Cartilha do Amazonas porque todas as palavras, as frases e os desenhos se referem a animais, fatos e costumes da região. Essa cartilha recebeu um prêmio nacional e duas edições dela já foram lançadas. Os alunos aprenderam rapidamente a ler e também aprenderam conceitos e idéias. Verdades que são perenes, úteis para toda a vida e que são apoiadas em conhecimentos científicos. Essa cartilha começou a ser utilizada em 1976 e milhares delas já foram distribuídas na Amazônia. A sua paralisação foi devida a um grupo de professores que consideravam que essa cartilha exigia muito da professora.

\section{A Sociedade Brasileira para o Progresso da Ciência}

Estudos Avançados - Como antigo dirigente da SBPC, como analisa o atual desempenho dessa entidade?

Warwick Kerr - Do ano passado para cá houve uma melhoria nas suas atividades em conseqüência da atuação de seu novo presidente, o Prof. Ênnio Candotti. Não votei nele, mas estou muito contente com seu desempenho. E se ele for novamente candidato, agora poderá contar com meu voto. Na última eleição, não o apoiei porque o Candotti deixou uma dívida enorme para o seu sucessor pagar, o Aziz Ab'Saber. Agora, disse-me ele que arranja dinheiro antes de programar as reuniões.

A SBPC está agora com seis mil sócios. É muito pouco, pois quando fui presidente tínhamos dezoito mil, se bem que no meu tempo a militância na entidade possuía outros atrativos, porque era a única organização em que se podia criticar a ditadura.

\section{Algumas opiniões de Warwick Kerr}

Zona Franca de Manaus - "Penso que foi útil para o estado do Amazonas e beneficiou Manaus, que hoje está com um milhão de habitantes, o que é algo monumental nos trópicos. Não sei se nela há transações discutíveis, mas pareceme que na Zona Franca a fiscalização é rigorosa."

Preservação da biodiversidade na Amazônia - "Deve ser ampliado o número de áreas de proteção ambiental e de parques federais, estaduais e municipais na Amazônia. Também é indispensável maior presença da polícia e maior atuação da Justiça.”

Posições partidárias - "Sou socialista. Em 1945 fui a uma reunião, em Piracicaba, do PCB. Ela era presidida pelo escritor Jorge Amado. Quando critiquei as teses de Lysenko sobre genética, aquele escritor respondeu que um assunto como esse deveria ser discutido somente na direção do partido. Nunca voltei a qualquer reunião comunista. Hoje eles estão francamente mudados. Entrei no Partido Socialista Brasileiro em Piracicaba. Fui eleito Vereador na legenda desse partido, mas quando me mudei para Rio Claro e fui escolhido Diretor Científico da Fapesp, 
solicitei meu desligamento, porque queria deixar claro que Fapesp não tomaria qualquer posição política partidária. Quando o PT foi fundado, em 1980, ingressei nele, mas agora estão aumentando minhas divergências com esse partido, como no caso da expulsão da senadora Heloisa Helena, na questão da aposentadoria dos professores, na votação do salário mínimo, nas altas taxas de juros etc." Atuação dos militares na Amazônia - "Eles trabalham muito bem na área da educação, realizam um bom controle nas questões de saúde e preparam nossos soldados para a defesa do país, tendo em vista a situação de cada local na Amazônia."

Transposição das águas do São Francisco - "Estive há pouco tempo naquele rio, inclusive o atravessei a pé. Não há possibilidade de transpor suas águas para o nordeste setentrional. $\mathrm{O}$ governo deveria estudar, isso sim, a possibilidade de levar um terço da água do Tocantins para o semi-árido, o seria uma solução definitiva e que resultaria na construção de trinta cidades de alto padrão.” 